\title{
A Study of Joint Venture Formation between Construction Organizations in Tanzania
}

Steven J. Minja, and Geraldine J. Kikwasi (Ardhi University, Tanzania)

Wellington D. Thwala (University of Johannesburg, South Africa)

\begin{abstract}
Formation of joint ventures between construction companies is one of the recent efforts in combating contractors problems in Tanzania and addresses one of the key challenges facing the construction industry today in the country especially when large and complex projects are involved. The main objective of the research is to examine the formation of joint ventures in Tanzania, specifically to: study joint ventures formation procedures; identify criteria in selection of joint venture partner; and identify risks associated with and challenges facing joint venture undertakings in Tanzania. The study adopted a descriptive research design and purposive sampling. Multiple sources of evidence was used to collect information mainly literature review, questionnaires and interviews. Key findings reveal that legal and statutory requirements in the formation of joint ventures include registration by Business Registration and Licensing Agency (BRELA), Contractors Registration Board (CRB) and under Registration of Documents Act (RDA). All JV respondents were registered by BRELA and CRB which are mandatory but only 7 were registered by RDA. Most important factors considered during formation of JVs are: contract agreement, financial stability and commitment while key risks associated with JVs are cultural and social differences, delays in approvals and financial risks. In addition, main challenges facing joint ventures are: identification of possible risks and joint venture agreement interpretation. The study concludes that formation of JVs have been addressing some of emerging challenges facing local construction organizations despite the risks and challenges that exist. The study recommends that firms entering joint ventures should explore the benefits of registering with RDA and ensure risks associated with their JV are properly assessed. The study also recommends introduction of an incentive scheme through Tanzania Investment Centre to grant tax relief for foreign contractors going into joint venture with local construction firms.
\end{abstract}

Keywords: Construction organizations, joint ventures, process, risks, challenges

\section{Introduction}

Joint venture formation between construction companies is one of the recent efforts in combating contractors problems in Tanzania and addresses one of the key challenges facing the construction industry today in the country especially when large and complex projects are involved. Construction joint ventures are formed for a number of reasons including pooling of resources, sharing of risks, undertaking large and complex projects, entry to a foreign market and business diversification (Minja, 1986; Dalle and Ports, 1999; Kwok, Then and Skitmore, 2000; Adnan and Morledge, 2003).

In formation of joint venture interested parties need to set criteria that will lead to successful execution of envisaged construction project. Various studies (Kwok, Then and Skitmore, 2000; Adnan and Morledge, 2003; Rowan 2005; Adnan, Chong and Morledge,2011) have identified criteria pertinent to JV partner selection such as ability, experience and skills, financial stability, partners' commitment, understanding and commitment to JV objectives, inter-partner trust and personal knowledge of the partner organizations.

Risks are inherent in construction Joint venture is not an exception some of the risks such as the agreement of the contract, partner selection, potential financial distress in JV partner, improper project feasibility study, project delay, inadequate forecast about market demand, 
loss due to bureaucracy for late approvals and design changes have been identified worldwide (Kwok et al, 2000; Shen, Wu and Catherine, 2001; Adnan and Morledge, 2003; Rowan 2005; Adnan, 2008; Jamil, Mufti and Khan, 2008; Adnan et al, 2011). Likewise construction joint ventures face challenges which to be known addressed by the potential partners. The purpose of this research is to examine the formation of joint ventures in Tanzania particularly, JV formation procedures, partner selection criteria and associated risks.

\section{Review of Literature}

\section{Overview of Joint Venture}

Gaeton and Keith (1999) state important resources to successfully undertake construction projects to completion as: adequate financial resources, managerial skills, plant and equipment, appropriate technology and skilled and unskilled labour. Depending on the nature of the project, at times these resources are not readily available to construction organizations thus necessitating formation of joint ventures. A number of authors (Gaeton and Keith 1999; Wolf, 2000; Miller, 2002; Watermeyer, 2005) have defined joint venture broadly, basically as a partnership or coalition between two or more companies which can be short or long term to carry out an activity.

Globally, construction businesses are becoming more competitive due to complexity of clients requirements and technology advancement. Construction organizations are forced to form alliances at varying levels in order to stay in business. Some of the reasons dictating such alliances include: surfacing of large and complex projects; pooling of resources; sharing of risks; entry to foreign market; access to technological improvements; political or diplomatic improvements; tied aids (Minja, 1986; Dalle and Ports, 1999). By pooling resources and complementary strengths companies can increase productivity and competitive standing in ways they could not do by themselves. It is important for companies which are considering entering into a joint venture to examine strategies applied in order to uncover what makes them successful (or unsuccessful) and why they work differently in different situations (Kathryn, 1986). In general joint ventures are not the easiest forms of organisation to manage and operate. Therefore there must be compelling reasons why parties to a construction contract resort to the formation of a joint venture in contrast to the conventional contractor/subcontractor relationship (Dalle and Ports, 1999).

Adnan and Morledge (2003) identify important objectives to be achieved through joint venture works which are: new market opportunity, profit, financial objectives, increased project scale, reducing risks and organizational learning. Similarly Kwok, Then and Skitmore (2000) have listed motivators for joint ventures in Singapore as strategic market entry, business diversification, sharing of resources and risk sharing.

\section{Joint Venture Agreements}

The joint venture agreement on a sophisticated international construction project is a complex document that usually is the product of extensive negotiations between the parties. There is no single standard form of Joint Venture Agreement because there can be a range of characteristics. But general consideration of Joint Venture Agreement should bear in mind important issues as follows (Rowan, 2005):

- $\quad$ defines the parties to the agreement;

- $\quad$ defines the purposes and objectives of the joint venture;

- defines the monetary and non-monetary contributions to be made by each of the parties;

Minja, S.J., Kikwasi, G.J., and Thwala, W.D. (2012) 'A study of joint venture formation between construction organization in Tanzania', Australasian Journal of Construction Economics and Building, Conference Series, 1 (2) 32-42 
- defines the management and structure of the joint venture and the associated appointment mechanism;

- $\quad$ defines the (corporate) vehicle under which the joint venture will be carried on;

- defines the basis on which the participants share in the profits and losses of the joint venture;

- $\quad$ defines the liabilities of the joint venture partners;

- $\quad$ provides for a conflict resolution mechanism, and

- $\quad$ provides for a termination mechanisms.

Joint venture agreements depend on the form of joint venture adopted. Rowan (2005) indicates three forms of joint ventures which are: joint venture in form of company; joint venture in form of partnership; and joint venture on contractual basis (unincorporated joint venture).

\section{Joint Venture Partner Selection}

Prior to selection of a joint venture partner firms aspiring to form joint ventures should formulate or adopt criteria that will guide their undertakings. The main criteria considered when an organization is looking for possible partners to go into joint venture partnership are as follows (Rowan 2005):

Ability, experience and skills: Require organization with proven ability experience and skills

Financial stability: Financial suitability is an important requirement for joint venture partnership

Similar business philosophy and concepts: This factor constitutes a basis for building a cohesive team with common goals

Strength of partner's willingness to form joint ventures: The joint venture must be driven by both parties

Spoken language: Most contractors prefer to look for partners abroad who speak the same language to avoid communication problems

Kwok, Then and Skitmore (2000) reveal criteria used in selection of a joint venture partner in Singapore as partners' commitment, understanding and commitment to JV objectives, past $\mathrm{JV}$ experience, compatibility between partners and understand own and shared risks. Adnan and Morledge (2003) identify criteria for partner selection among12 critical success factors for joint venture projects. Additionally, Adnan, Chong and Morledge (2011) identify critical factors in the international JV partner selection in which criteria were related to the reputation, inter-partner trust, experience, personal knowledge of the partner organizations, commitment and human resources management

\section{Risks in joint venture undertakings}

Joint venture undertaking involves risks that need to be known to the partners such that appropriate measures can be taken. Adnan (2008) identifies risk factors in joint venture formation in Malaysia as the agreement of the contract, partner selection, control/equity, sub-contractors, renegotiations and training. Other most important risk factors in Singapore were revealed by Kwok et al (2000) and these are disagreement in accounting profit and loss, potential financial distress in JV partner, potential financial distress in JV, partner's lack of management competence and resourcefulness, over-interference by parent companies of either parties, and disagreement in allocation of work.

Minja, S.J., Kikwasi, G.J., and Thwala, W.D. (2012) 'A study of joint venture formation between construction organization in Tanzania', Australasian Journal of Construction Economics and Building, Conference Series, 1 (2) 32-42 
A number of studies have identified risks in construction joint venture undertakings in various parts of the world. Jamil et al (2008) identify 10 most important risks in international joint venture as financial risks due to delays in payments, foreign currency fluctuation, incompatibility of local policies with international practice, pollution and safety rules, changes in laws and regulations, design problems, inflation and cost overrun, delays in approvals and permits from government, inadequate technical specifications in tender documents and site access/right of way. Shen et al (2001) identify top ten risks in construction joint venture in China and these are: cost increase due to changes of policy, improper project feasibility study, project delay, inadequate forecast about market demand, improper selection of project location, improper selection of project type, increase of resettlement costs, inadequate choice of project partner, loss due to bureaucracy for late approvals and design changes.

\section{Challenges Facing Joint Ventures}

Challenges are part of any project undertakings including joint ventures. According to Watermeyer (2005) the following are the challenges facing construction companies going into joint ventures:

- $\quad$ identification of possible risks likely to be in a joint venture undertaking and finding ways which will enable losses to be minimized and opportunities to be maximized;

- $\quad$ to determine forms and reasons for joint venture formation most appropriate in Tanzania;

- $\quad$ how to grade a joint venture capability and capacity;

- $\quad$ how to encourage joint venture formation, assuming that it is a desirable practice;

- decision on how two or more contractors with different capacities can enter into joint venture agreement; and

- how does one prevent misinterpretation of the facts in order to influence the tender process or the award of a contract arising from a tender offer or collusive practices intended to subvert developmental objectives during the period of performance of the contract.

\section{Methodology}

\section{Research design}

The research design of this study is descriptive which is attempting to put to light issues on construction joint venture formation in Tanzania.

\section{Population and Sample size}

The population of the study is the number of projects registered by Contractors Registration (CRB) undertaken under joint venture arrangement between 2007 and 2010. Statistics from $\mathrm{CRB}$ indicates that the number of Joint ventures registered during the period were 102 . The sample size was 45 comprising 30 of joint ventures, 10 consultants and 5 statutory bodies.

\section{Sampling procedure}

Some criteria were set to obtain the sample from joint ventures and these are: at least one of joint venture partner has the office located in Dar es Salaam for easy communication and has execute a project with a value of not less than TAS 500 million. Using the criteria, only 30 joint venture companies were selected. Consulting firms involved in the study were selected basing on the fact that they were established before 2001 and therefore have been

Minja, S.J., Kikwasi, G.J., and Thwala, W.D. (2012) 'A study of joint venture formation between construction organization in Tanzania', Australasian Journal of Construction Economics and Building, Conference Series, 1 (2) 32-42 
in practice for over ten years, and have been involved in joint venture projects for between two to six years. Purposive sampling was used to select consultants from quantity surveying, architectural firms and statutory and consultative bodies.

\section{Data Collection}

Multiple sources of evidence were used to collect data. Literature was reviewed to establish what has been written on formation of joint ventures between construction firms. Questionnaires were sent to selected joint ventures, consulting firms, statutory and consultative bodies. Statutory and consultative bodies are: Business and Licensing Agency (BRELA), Contractors Registration Board (CRB), Architects and Quantity Surveyors Registration Board (AQRB), Public Procurement Regulatory Authority (PPRA) and National Construction Council (NCC). Responses from the respondents are indicated in Table 1 below.

Table 1: Responses from Consultants, Statutory Bodies and Joint Ventures

\begin{tabular}{|c|l|c|c|}
\hline S/N & Respondent & $\begin{array}{c}\text { Questionnaires } \\
\text { sent }\end{array}$ & $\begin{array}{c}\text { Questionnaires } \\
\text { received }\end{array}$ \\
\hline 1 & $\begin{array}{l}\text { Statutory and consultative } \\
\text { Bodies (AQRB, CRB, BRELA, }\end{array}$ & 5 & 5 \\
\hline 2 & Cons and NCC) & 10 & 6 \\
\hline 3 & Joint Venture Companies & 30 & 24 \\
\hline & Total & $\mathbf{4 5}$ & $\mathbf{3 5}$ \\
\hline
\end{tabular}

\section{Analysis and Discussion}

The process of data process was done by arranging the collected data in frequency tables and then computing mean, standard deviation and relative importance index. Relative Importance Indices (RIIs) and cross comparison tables are then used to rank the results obtained.

- $\quad$ Calculation of Mean: This is the average of all values in a set of data. The mean is calculated by adding all the values in then group and then dividing by the number of values.

- Standard deviation: This is the measure of the degree to which data is spread around the mean. It is a positive square root of the variance. Standard Deviation is calculated as follows:

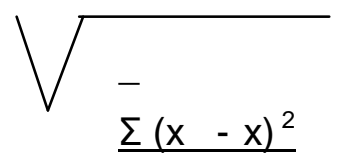

$\mathrm{N}$

Where

$\mathrm{X}=$ Value,$\quad{ }^{-} \mathrm{X}=$ Mean value, $\mathrm{N}=$ total number of respondents 
- $\quad$ Relative Importance Index (RII): This is calculated as follows:

$\mathrm{RII}=\Sigma \mathrm{W} / \mathrm{AxN}$

Where;

$\mathrm{W}=$ weight given to each factor by respondents

$A=$ highest weight, $N=$ total number of respondents.

Relative Importance Indices (RIIs) comparison tables can be used to rank the results by taking into account the average scores and the RII as follows:

Table 2: Relative Importance Indices (RIIs) comparison tables

\begin{tabular}{|l|c|l|}
\hline Average Score & RII & Rankings \\
\hline 4.0 to 5.0 & 0.80 to 1.00 & High $(\mathrm{H})$ \\
\hline 3.0 to 4.0 & 0.60 to 0.80 & Medium (M) \\
\hline 1.0 to 3.0 & 0.20 to 0.60 & Low (L) \\
\hline
\end{tabular}

Source: Chileshe, Haupt and Fester (2007)

\section{Respondents' Profile}

The joint ventures involved in the study comprised of 12 local to local, 10 local to foreign and 2 foreign to foreign joint ventures. Statutory bodies selected have the following roles: BRELA which is responsible for registration of companies; CRB which is responsible for registration of contractors; AQRB is responsible for registration Architects and Quantity Surveyors; PPRA is responsible for regulating procurement of public services and goods; and NCC is an institution that gives directives on construction related matters. Consulting firms comprised of architectural and quantity surveying firms.

\section{Process of Formation of Joint Ventures}

The formation of joint venture between two companies in Tanzania like in many other countries involves registration with various entities namely: BRELA, CRB and under Registration of Documents Act (RDA). Registration with BRELA and CRB is mandatory; however, registration under RDA is optional. Assessment of 24 joint ventures registration status is indicated in Table 3 below.

Table 3: Registration of JVs by BRELA, CRB and under RDA

\begin{tabular}{|c|l|c|}
\hline S/NO & ENTITY & JVs \\
\hline 1 & Registration by Business Registrations (BRELA) & 24 \\
\hline 2 & Contractors Registration Board (CRB) & 24 \\
\hline 2 & Registration of Documents Act (RDA) & 7 \\
\hline
\end{tabular}

Minja, S.J., Kikwasi, G.J., and Thwala, W.D. (2012) 'A study of joint venture formation between construction organization in Tanzania', Australasian Journal of Construction Economics and Building, Conference Series, 1 (2) 32-42 
Results in Table 3 above indicate that all joint ventures were registered by BRELA and CRB and only 7 were registered by RDA. The fact that registration by BRELA and CRB is mandatory and no company in Tanzania can undertake any construction work without fulfilling it, all JVs were registered and they did not find any importance of registering with RDA. The joint venture companies obviously overlook the advantage of this registration which gives more weight to the document as the registration gives more confidence and trust to the partners themselves and even to the outsiders who wish to join the joint ventures.

\section{Forms of Joint Ventures in Construction Projects in Tanzania}

There are three forms of joint ventures classified as integrated, non-integrated and combination joint ventures. Responses on the type of joint ventures commonly applicable in Tanzania are as shown in Table 4 below.

Table 4: Forms of Joint Ventures

\begin{tabular}{|c|l|c|c|}
\hline S/N & Type & Total & Ranking \\
\hline 1 & Integrated JV & 19 & 1 \\
\hline 2 & Non -Integrated JV & 8 & 2 \\
\hline 3 & Combination JV & 2 & 3 \\
\hline
\end{tabular}

Basing on Table 4 above the most preferred form of joint venture is integrated followed by non-integrated. These results suggest that integrated joint venture is preferred due to the fact that it involves sharing profits and losses by $50 \%$ - $50 \%$ and therefore reducing investment risks.

\section{Factors guiding selection of a JV partner}

Selection of joint venture partners is a crucial factor which determines the success of the joint venture undertaking. Some aspects must be carefully considered before the selection of appropriate partner is done. A list of factors was compiled for joint ventures to assign weightings as follows: 4=Very Important, 3=Important, 2= Moderately Important, 1=Less Important and $0=$ Not Important at all. The results are summarized in Table 5 below.

Table 5: Key factors guiding selection of a JV partner- JVs

\begin{tabular}{|c|l|c|r|r|c|c|}
\hline S/N & Factor & Total & Mean & Std Dev. & RII & Rank \\
\hline 1 & Willingness & 90 & 3.75 & 0.44 & 0.94 & 1 \\
\hline 2 & Financial stability & 83 & 3.46 & 0.51 & 0.86 & 2 \\
\hline 3 & Competetiveness of required task & 80 & 3.33 & 0.70 & 0.83 & 3 \\
\hline 4 & Similar business philosophy & 71 & 2.96 & 1.12 & 0.74 & 4 \\
\hline 5 & Firm's ability & 68 & 2.83 & 0.96 & 0.71 & 5 \\
\hline 6 & Firm's experience & 48 & 2.00 & 1.14 & 0.50 & 6 \\
\hline 7 & Political stability & 44 & 1.83 & 1.05 & 0.46 & 7 \\
\hline 8 & Track record in JV's & 40 & 1.67 & 1.17 & 0.42 & 8 \\
\hline 9 & Spoken language & 36 & 1.50 & 0.98 & 0.38 & 9 \\
\hline
\end{tabular}

Minja, S.J., Kikwasi, G.J., and Thwala, W.D. (2012) 'A study of joint venture formation between construction organization in Tanzania', Australasian Journal of Construction Economics and Building, Conference Series, 1 (2) 32-42 
Results indicate that highly ranked key factors for success in joint ventures are willingness, financial stability and competitive of required task while similar business philosophy and firm's ability are considered to be medium. Similarly the factors were examined using responses from JVs and Consultants and the results are shown in Table 6 below.

Table 6: Key Factors guiding selection of a Joint Venture partner- Consultants and JVs

\begin{tabular}{|c|l|c|c|c|c|c|}
\hline S/N & Factor & Total & Mean & Std Dev. & RII & Rank \\
\hline 1 & Contract agreement & 109 & 3.63 & 0.56 & 0.91 & 1 \\
\hline 2 & Financial stability & 100 & 3.33 & 0.61 & 0.83 & 2 \\
\hline 3 & Commitment & 97 & 3.23 & 0.77 & 0.81 & 3 \\
\hline 4 & Mutual understanding & 88 & 2.93 & 0.87 & 0.73 & 4 \\
\hline 5 & Coordination & 84 & 2.80 & 0.96 & 0.70 & 5 \\
\hline 6 & Cooperation & 59 & 1.97 & 1.00 & 0.49 & 6 \\
\hline 7 & Partner selection & 57 & 1.90 & 0.96 & 0.48 & 7 \\
\hline 8 & Local conditions & 50 & 1.67 & 1.15 & 0.42 & 9 \\
\hline 9 & Communication & 51 & 1.70 & 0.95 & 0.43 & 8 \\
\hline 10 & Past experience & 13 & 0.43 & 1.04 & 0.11 & 10 \\
\hline
\end{tabular}

Results of combined responses indicate that highly ranked key factors for success in joint ventures are contract agreement, financial stability and commitment while mutual understanding and coordination are considered to be medium.

\section{Risks associated with Joint Venture undertakings in Tanzania}

It is desirable for construction firms to identify the risks and find probable impact of these risks as early as possible, so that suitable strategies are made before actual execution of project commences. Risks in international construction projects are more critical as compared to domestic projects because they play a vital role for successful project delivery and increase efficiency and profitability of construction projects (Jamil, Mufti and Khan, 2008). Assessment of risks associated with joint venture formation in Tanzania is summarized in Table 7 below.

Basing on Table 7, the highly perceived risks are cultural and social differences, delays in approvals and financial risks while foreign currency fluctuation, loss of trust, incompatibility of local policies with international practice, termination of joint venture agreements and cost escalation were perceived to be medium. In international joint ventures, incompatibility of local policies with international practice affects mainly the foreign partner who is not familiar with the policies of the host country. Therefore in planning for joint ventures there is a need to minimize or eliminating such risks through identifying, assessing, analyzing, ranking risks and finally developing handling options. Fluctuations in rates directly impact on projects which have a significant component of imports but all remaining types of projects also get affected to some extent.

Minja, S.J., Kikwasi, G.J., and Thwala, W.D. (2012) 'A study of joint venture formation between construction organization in Tanzania', Australasian Journal of Construction Economics and Building, Conference Series, 1 (2) 32-42 
Table 7: Risks in JV undertakings in Tanzania

\begin{tabular}{|c|l|c|c|c|c|c|}
\hline S/N & Risk & Total & Mean & Std Dev. & RII & Rank \\
\hline 1 & Cultural and social differences & 103 & 3.43 & 0.68 & 0.86 & 1 \\
\hline 2 & Delays in approvals & 98 & 3.27 & 0.78 & 0.82 & 2 \\
\hline 3 & Financial risks & 97 & 3.23 & 0.73 & 0.81 & 3 \\
\hline 4 & Foreign currency fluctuation & 94 & 3.13 & 0.73 & 0.78 & 4 \\
\hline 5 & Loss of trust & 92 & 3.07 & 0.91 & 0.77 & 5 \\
\hline 6 & Incompatibility with local policy & 90 & 3.00 & 0.87 & 0.75 & 6 \\
\hline 7 & Termination of JV agreements & 89 & 2.97 & 0.67 & 0.74 & 7 \\
\hline 8 & Cost Escallation & 80 & 2.67 & 0.92 & 0.67 & 8 \\
\hline 9 & Poliyical stability & 66 & 2.20 & 0.81 & 0.55 & 9 \\
\hline
\end{tabular}

\section{Challenges facing JVs Undertakings in Tanzania}

Joint ventures may encounter challenges during the course of execution of joint venture projects or even at the close out stage. These challenges may have repercussions on the joint venture and therefore they should be well planned ahead of contract implementation to avoid frustration or even termination of joint venture agreement. Table 8 below summarizes challenges facing JVs.

Table 8: Challenges facing JV Undertakings in Tanzania

\begin{tabular}{|c|l|c|c|c|c|c|}
\hline S/N & Challenge & Total & Mean & Std Dev. & RII & Rank \\
\hline 1 & Identification of Possible Risks & 103 & 3.43 & 0.77 & 0.86 & 1 \\
\hline 2 & JV Agreement Interpretaion & 100 & 3.33 & 0.84 & 0.83 & 2 \\
\hline 3 & Operations by Different Contractors & 94 & 3.13 & 0.82 & 0.78 & 3 \\
\hline 4 & Alignment of Partner Strategies & 90 & 3.00 & 0.69 & 0.75 & 4 \\
\hline 5 & Management Control over Local JV & 86 & 2.87 & 1.07 & 0.72 & 5 \\
\hline 6 & Grading JV ability and capacity & 78 & 2.60 & 1.04 & 0.65 & 6 \\
\hline 7 & Competitive cost Structure & 59 & 1.97 & 0.81 & 0.49 & 7 \\
\hline 8 & Joint Venture Formation & 54 & 1.80 & 1.24 & 0.45 & 8 \\
\hline 9 & Establishing Joint Goals & 47 & 1.57 & 1.19 & 0.39 & 9 \\
\hline 10 & Tender document Pricing & 43 & 1.43 & 1.04 & 0.36 & 10 \\
\hline
\end{tabular}

Results in Table 8 above reveal that the highly perceived challenges in JVs undertakings are identification of possible risks and joint venture agreement interpretation followed by operations by different contractors, alignment of partners strategies, management control over local joint venture and grading joint venture ability and capacity which are perceived as medium. This suggests that prior to entering into joint venture agreements, joint venture partners must satisfy themselves that the undertaking has overcome all possible risks and set procedures to settle such problems should they occur in the course of executing the contract. However due to the urgency of drawing up the contract and joint venture formation

Minja, S.J., Kikwasi, G.J., and Thwala, W.D. (2012) 'A study of joint venture formation between construction organization in Tanzania', Australasian Journal of Construction Economics and Building, Conference Series, 1 (2) 32-42 
some of these aspects may be overlooked resulting into problems during the course of executing the contract.

\section{Conclusions and Recommendations}

\section{Conclusion}

Formation of joint ventures between construction organizations has been an important endeavour in overcoming problems facing local contractors such as inadequate work opportunities, weak financial capability, lack of plant / equipment and lack of management skills. These problems can be addressed by forming joint ventures between foreign and local, local and local or foreign and foreign companies. The usual purpose of joint venture is to spread a risk inherent in large projects and to pool resources in a way that permits to execute a project.

The formation of joint venture companies in Tanzania need to follow all legal and statutory requirements including registration with registration by Business Registrations and Licensing Agency (BRELA), registration by Contractors Registration Board (CRB) and registration under Registration of Documents Act (RDA). In planning for a joint venture arrangement, it is important to consider all important factors in order to have a project delivered successfully. Factors that guide joint venture formation in Tanzania are contract agreement, financial stability and commitment. The most important risks associated with joint venture undertakings are cultural and social differences, delays in approvals and financial risks. Similarly, joint ventures as any other undertaking do encounter challenges. Challenges facing joint ventures in Tanzania include: identification of possible risks and joint venture agreement interpretation.

\section{Recommendations}

Based on the findings and conclusion of this study, it is recommended that firms entering joint ventures should explore the benefits of registering with RDA and ensure risks associated with their JV are properly assessed. The study also recommends introduction of an incentive scheme through Tanzania Investment Centre to grant tax relief for foreign contractors going into joint venture with local construction firms.

\section{References}

Adnan, H. 2008. An assessment of risk management in joint venture projects in Malasyia, Asian Social Sciences, 4 (6) pp 99-106

Adnan, $\mathrm{H}$ and Morledge, R. 2003. Joint Venture Projects in Malaysian Construction Industry: Factors Critical to Success, A Paper presented at the 19th Annual Association of Researchers in Construction Management Conference, University of Brighton, Malaysia.

Adnan, H. Chong, H.Y and Morledge, R. 2011. Success criteria for international joint ventures: The experience of Malaysian contractors in the Middle East. African Journal of Business Management 5(13), pp. 5254-5260

Aimin, Y. and Yadong, L. 2001. International Joint Ventures: Theory and Practice, 2nd Edition, M. E. Sharpe, Inc, 80 Business Park Drive, Armonk, New York 10504, United States of America.

Bairi, M. and Njaa, S. 2005. Registration of Joint Ventures Contracting Firms, A Paper presented in a Workshop on Joint Ventures Partnership for Contractors in Tanzanian, 14th and 15th April, Dar-EsSalaam, Tanzania.

Chileshe, N, Haupt, T., and Fester, F. 2007. Assessing the Readiness of Building Diplomates for the South African Construction Industry, Journal for Education in the Built Environment, 2 (2)

Minja, S.J., Kikwasi, G.J., and Thwala, W.D. (2012) 'A study of joint venture formation between construction organization in Tanzania', Australasian Journal of Construction Economics and Building, Conference Series, 1 (2) 32-42 
Dalle, G .and Potts, K. 1999. Joint ventures in the construction industry, A Paper presented at the Annual Workshop, School of Engineering and the Built Environment, University of Wolverhampton, UK

Gaeton, D. and Keith, P. 1999. Joint Ventures in the Construction Industry, School of Engineering and the Built Environment, University of Wolverhampton, UK

Jamil, M., Mufti, N.A.and Khan, A.H. 2008. Risk Identification for International Joint Venture Construction Projects, First International Conference on Construction In Developing Countries (ICCIDC-I), Karachi, Pakistan

Kathryn, R. H. 1985. Joint Ventures, Alliances, and Corporate Strategy, Beard Books, New York.

Kathryn, R. H. 1986. Managing for Joint Venture Success, Lexington Books, New York.

Kwok, H.C.A. and Then, D. and Skitmore, M. 2000. Risk management in Singapore construction joint ventures. Journal of Construction Research 1(2):pp. 139-149.

Minja, S. J. 1986. Joint Ventures between Local and Foreign Construction Firms, Problems and Prospects, ARI, Dar Es Salaam.

Rockart, J.F. 1994. The changing role of the information systems executive: a critical success factors perspective. Sloan Management Review. 241(1), 3-13.

Rowan, V. 2005. How joint ventures are organized, operated on international construction projects. An outline used in the presentation to the Overseas Construction Association of Japan, Inc. (OCAJI)

Shen, L. Y., Wu, G. W. C., and Catherine S. K. N. 2001. Risk assessment for construction joint ventures in china. Journal of Construction Engineering and Management, 127 (1), pp 76-81 source: http//jingpin.szu.edu.cn accessed on 31/5/2012

Watermeyer, R. 2005. Fundamentals of a Joint Venture, A Paper presented in a

Wolf, R. C. 2000. Effective International Joint Venture Management, M .E.Sharpe, Inc 80 Business Park Drive, Armonk, New York 10504. 